\title{
An Empirical Study on the Development of Intercultural Network in Northeast Asian Sea Region - Focusing on the Foreigner Residence of Dejima and Choryang Waegwan -
}

\author{
Mi-Hee Kong1), Ha-Kyun Kim²)
}

\begin{abstract}
Dejima and Choryang Waegwan are resident areas established by the government to accommodate the Dutch and Japanese traders respectively who came for commercial trade activities. This was established to prevent the local citizens to communicate with the foreigners. Dejima and Choryang Waegwan have both similarities and differences on their purpose of establishment, which reflects the way of life and intercultural exchange of the foreigners. This is an empirical study that investigates the trade operations and way of life of the foreigners in the settlement areas on the Northeast Asian Sea Region cross-cultural network. Therefore, This paper analyzes the relationship between the trade operations and way of life in the settlement areas based on the establishment of schools, the expansion of surrounding facilities, and the spread of western studies. We also empirically analyzed the perception of each factor by setting up a model related to how it affected the foundation of modernization of both countries. A structural equation model was adopted to test the relationship between the factors described above. The summary of the study is as follows. First, settlement areas and the spread of western studies were found to have a significant effect in Dejima and Choryang Waegwan. Second, settlement areas and school establishment were found to have a significant effect in Dejima and Choryang Waegwan. Third, settlement areas and expansion of surrounding facilities were found to have a significant effect. Fourth, the dissemination of western studies and foundation of modernization had a significant effect in Dejima but not in Choryang Waegwan. Fifth, school establishment and the foundation of modernization had a significant effect in Dejima and Choryang Waegwan. Sixth, the expansion of the surrounding facilities and foundation of modernization did not show a significant effect in Dejima and Choryang Waegwan.
\end{abstract}

Keywords: Foreigners' Settlement Areas, Dissemination of Western Studies, School Establishment, Expansion of Surrounding Facilities, Foundation of Modernization

\section{Introduction}

This study attempts to empirically analyze the recognition of intercultural networks of Dejima

Received(September 25, 2019), Review Result(1st: October 21, 2019, 2nd: December 08, 2019), Accepted(January 30, 2020)

1) (Research Professor, First Author) 48513 Humanities Korea Plus Research Group, Pukyoung National Univ. 45, Yongso-ro, Nam-Gu. Busan, Korea

email: kongmihe@pknu.ac.kr

2) (Professor, Corresponding Author) 48513 Division of Business, Pukyoung National Univ. 45, Yongso-ro, Nam-Gu. Busan, Korea

email: kimhk@pknu.ac.kr 
An Empirical Study on the Development of Intercultural Network in Northeast Asian Sea Region - Focusing on the Foreigner Residence of Deiima and Choryang Waegwan -

in Nagasaki and Choryang Waegwan in Busan Based on reference[1] As a reconsideration the continuity of pre-modern process of forming the humanities network of the modern Northeast Asian Sea Region. Dejima and Choryang Waegwan are settlement areas established in the 17th century by the government to separate from the society the foreigners, Dutch or Japanese, who came for commercial trade activities in certain areas. Both foreign settlements have commonalities in their purpose of establishment, but they also differ in their cultural life and intercultural exchanges with the countries to which they reside. In Korea, research on Dejima is insufficient. A comparative study was conducted on the establishment process, purpose, management and operation of settlement areas in Choryang Waegwan and Dejima[1][2]. In addition, research on the nature of Waegwan and crimes that occurred in Waegwan continued[3-6]. However, these findings did not find any key factors that contributed to the social development of modernization that can be obtained from historical facts. Dejima, which served as a gateway to western science and technology and cultural acceptance, has been an opportunity for modernization in Japan, but it has been difficult to find a study on the relationship between Choryang Waegwan and modernization[1].

This paper analyzes the relationship between the trade operations and way of life in the settlement areas based on the establishment of schools, the expansion of surrounding facilities, and the spread of western studies. We also empirically analyzed the perception of each factor by setting up a model related to how it affected the foundation of modernization of both countries. A structural equation model was adopted to test the relationship between the factors described above.

\section{Theoretical Background}

\subsection{Settlement Areas}

The most famous foreigners' settlement areas in Japan and Korea are Nagasaki's Dejima and Busan's Choryang Waegwan respectively. The Japanese shogunate built Dejima with the aim of stopping Christian propagating activity and accommodating Portuguese in various parts of the country to severely monitor trade. The seclusion order for the port of Portugal was fired in 1639 due to the policy of seclusion in 1635 and the Shimabara Rebellion in 1637. Therefore, all Portuguese living in Dejima departed to transfer the Dutch people staying in Hirado. Prostitutes, monks, and Japanese women could enter Dejima. However, free exchanges with other Japanese were not allowed. Therefore, intercultural exchange between the Japanese and 
Dutch people was restricted. However, once a year, the intercultural exchange was naturally carried out by Dutch interpreters and supervisors. On the other hand, in Choryang Waegwan, only the healthy men who were authorized by the Tsushima domain were entrusted by the shogunate to diplomatic trade with Koreans Monks and prostitutes who were previously allowed in Dejima were banned. The Korean government also established border zones of Waegwan, such as door, and restricted cross-cultural exchanges between the Koreans and the Japanese by prohibiting the entrance of the citizens. Many Koreans[7][8], such as the Tsushima people who stayed in Waegwan not only market foreign trade but also on the morning market held outside the main gate of Waegwan every morning. From here, intercultural exchange was formed.

\subsection{Dissemination of Western Studies}

Dutch studies developed in Japan were based on western studies. Science introduced by Dutch traders in Dejima covered many fields including medicine, mathematics, illness, astronomy, and mechanics. Academic knowledge, rational thinking, and the idea of human equality, which have arisen from Dutch studies, are thought to have had a great influence on the modernization of the Japanese society. Therefore, Dejima, where the Dutch trading house is located, was a space where intercultural exchanges took place with the spread of practical scholarship and technology in the West. and also the This is also the residence for the Japanese who had been approved by the Nagasaki Administration. In particular, Dr. Siebold, a medical doctor, had a great influence on the development of Japanese medicine. Many students from all over Japan studied new knowledge in Nagasaki, the gateway to western culture. They not only accepted European and Asian cultural property and information, but also learned languages such as Dutch, English, Chinese, along side medicine, natural sciences, military thought, which laid the foundation for Japanese modernization.

Choryang Waegwan is a settlement area where merchants with permission from Tsushima domain came to live. It can be said that Joseon was indirectly influenced by western culture through them. Choryang Waegwan opened up the place for intercultural exchange where Japan can be considered transformed. Before the port opened, it was restricted to the Japanese people. Later, this was made accessible to the Koreans. In Choryang Waegwan, conflict of interest also rose between the two countries in the process of intercultural exchange of Koreans and Japanese. However, western culture came indirectly through Japan, and Japanese modern culture and cultural property were brought directly into Busan, making it a center of new 
An Empirical Study on the Development of Intercultural Network in Northeast Asian Sea Region - Focusing on the Foreigner Residence of Deiima and Choryang Waegwan -

culture.

\subsection{School Establishment}

The establishment of schools in the settlement areas has a different effect on each country. Dr. Siebold, who was born in Germany and came to Dejima as a doctor in the Dutch trading house, became known as a western famous doctor since he began visiting Japan. Dr. Siebold opened the Narutaki school near Nagasaki to teach Japanese people not only medicine, but also western science, research and observation methods, and instrument usage. He is also a leader in the development of cross-cultural networks, such as disseminating western knowledge and information and exchanging Japanese information. When western studies flourished at the end of the Edo shogunate, Narutaki school became the starting point for learning western literature. In addition, the principles of application to medicine, zoology and botany, and science and technology inherited from Dr. Siebold became the basis of Japanese modernization after Meiji.

On the other hand, Amenomori-Hoshu, a Confucian scholar of Tsushima domain, learned Korean language from Choryang Waegwan. Then, in 1727, Korean Translation Agency was installed in Izuhara, Tsushima. As a strategy to invade Korea, the Meiji government needed to cultivate Korean language interpreters and in 1872, established the Korean Language School at Izuhara, Gwangcheongsa. The function of the Choryanggwan Language School was to have a politically cultivate the interpreters necessary for the Japanese government to enter Korea. However, it was not a modernization on education for the development of Korean society [9-11].

\subsection{Expansion of Surrounding Facilities}

Nagasaki shogunate administrator of Japan has allowed Dr. Siebold to open Narutaki School in the vicinity of Nagasaki as a facility expansion program. In addition, In Nagasaki, a treaty with five countries- the United States, the Netherlands, Russia, the United Kingdom, and France- was established in 1858 to create a residence for foreigners. After the opening, customs were established with an important position as a trading port, and the British consulate was built in Nagasaki from 1859. Many western-style buildings were built around Nagasaki Foreign settlement around the 1860s and 1900s, and the first western-style hotel was the "Commercial House" in 1862. In 1865, the British steam locomotive Iron Duke was first demonstrated in 
Japan, and in 1871 Nagasaki's first international telegraph started[11]. The Japanese government actively supported the expansion of peripheral facilities near Dejima for modernization, and foreigners also contributed much to Japan's modernization rather than to colonize Japan. On the other hand, as the surrounding facilities around Choryang Waegwan, Choryang Village, a Korean village was formed in the northern area of Waegwan, centered on Choryang customers, official translator buildings and government offices. It is a place where the social infrastructure necessary for trade and cross-cultural exchange has been established, and a human network has been formed. Since the opening of the port, Japanese public residences have been established, and regulations on the exchange between Koreans and Japanese have been relaxed, leading to an increase in commercial trade. The Japanese government established public institutions such as the Administrative Office (1879), the Chamber of Commerce (1881), the Telegraph Office (1884), and the Consulate (1884) as a project to expand the surrounding facilities, centering on all residences. North Port Reconstruction which was started to realize the strategy for the rule of Korea, is a reclamation site of Jungang-dong[12]. The reclaimed land has a large number of public infrastructure such as ports and railroad facilities, and commercial infrastructures such as shipping companies and transportation companies.

\subsection{Foundation of Modernization}

Edo Sanfu, an event in Dejima where Dutch officials build a procession and go to Edo, offering dedication to the Edo Shogunate for a year, was a chance for the Dutch to spread western studies to Japan. The doctors and scientists who accompanied the superintendent spread western studies and cultures to the Japanese through interpreters. In addition, academic knowledge, rational thinking, and the idea of human equality, which were created through Dutch studies, had a great influence on the modernization of Japanese society. Lectures on western studies, medicine, and science were provided at Siebold Narutaki educational facilities. Further, the establishment of a residence in Nagasaki in 1858 and the British Consulate in 1859, as well as the installation of submarine cables between Shanghai and Vladivostok in Nagasaki in 1871 by expanding the surrounding facilities took place. In this way, the spread of western scholarships and the establishment of schools and expansion of surrounding facilities through Dutch studies in a foreign settlement, Dejima, laid the foundation for Japan's modernization. On the other hand, Choryang Waegwan has been changed to a residence in Japan after the port opening and was the center of new culture in which western cultural property and Japanese modern culture flow. However, Japan's exercise of diplomatic rights and 
An Empirical Study on the Development of Intercultural Network in Northeast Asian Sea Region - Focusing on the Foreigner Residence of Dëima and Choryang Waegwan -

extraterritorial legislation was recognized, making it an outpost of colonization. The Choryanggwan Language School was mainly of political nature to train interpreters necessary for the Japanese government to enter Korea. In addition, as a project to expand the surrounding facilities, a reconstruction work was carried out for the construction of public institutions such as the Administrative Office (1879), the Chamber of Commerce (1881), the Telegraph Office (1884), and the Consulate (1884).

\section{Research Design}

\subsection{Research Model}

This is an empirical study that investigates the trade operations and way of life of the foreigners in the settlement areas in the Northeast Asian Sea Region cross-cultural network. It focuses on analyzing the impact of settlement areas on the spread of western studies, school establishment and expansion of surrounding facilities. Based on the previous research, the research model is presented in [Fig. 1].

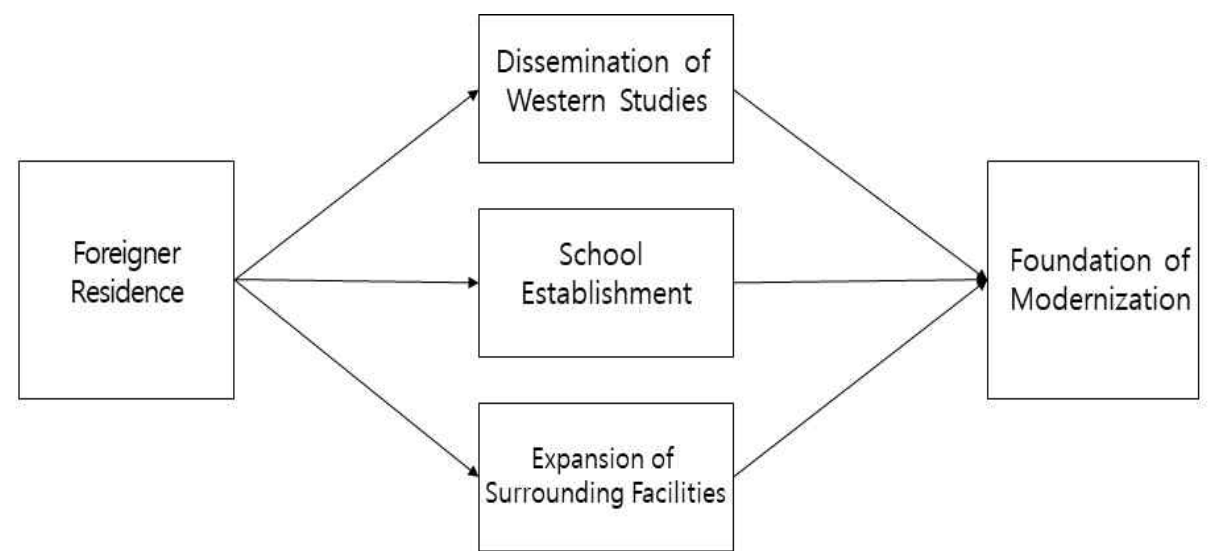

[Fig. 1] Research Model

\subsection{Research Hypothesis}

\subsubsection{The Hypotheses on the Settlement Areas and Modernization Formation}

Hypothesis was set whether settlement areas affects formation factors of modernization. The formation factors of modernization were divided into three categories: dissemination of western studies, school establishment, and expansion of surrounding facilities. Therefore, the hypothesis 
is as follows.

Hypothesis 1: Settlement areas for the foreigners will have a significant impact on the formation of modernization.

Hypothesis H1-1: Settlement areas for the foreigners will have a significant impact on the dissemination of western studies.

Hypothesis H1-2: Settlement areas for the foreigners will have a significant impact on school establishment.

Hypothesis H1-3: Settlement areas for the foreigners have a significant impact on the expansion of surrounding facilities.

\subsubsection{The Hypotheses on the Modernization Formation and Foundation of Modernization}

This study hypothesized whether modernization formation affects the foundation of modernization. Therefore, the hypothesis is as follows.

Hypothesis 2: Formation of modernization will have a significant impact on the foundation of modernization.

Hypothesis H2-1: Dissemination of western studies will have a significant impact on the foundation of modernization.

Hypothesis H2-2: School establishment will have a significant impact on foundation of modernization.

Hypothesis H2-3: Expansion of surrounding facilities will have a significant impact on the foundation of modernization.

\subsection{Empirical Analysis and Results}

\subsubsection{Data Collection and Sample Characteristics}

A total of 120 users answered the survey of this study. The basic questionnaire was conducted after reading the three-page summary of the basic data of Dejima and Choryang Waegwan. Data was collected through university students and Google surveys. The basic statistics are as follows: $62 \%$ of the respondents used male and $48 \%$ were female. The proportion of men is higher than that of women. Next, the mean age was 25.7 years. Most of the respondents are young. The occupation was the highest with $44 \%$ of students, followed by $21 \%$ self-employed, $15 \%$ of employees and others.

\subsubsection{Method of Analysis of Data}


An Empirical Study on the Development of Intercultural Network in Northeast Asian Sea Region - Focusing on the Foreigner Residence of Deiima and Choryang Waegwan -

For questionnaire analysis, the basic statistics were SPSS 22.0. Smart PLS 2.0 was used for structural equation analysis.

[Table 1] Reliability and Internal Consistency

\begin{tabular}{|c|c|c|c|c|c|}
\hline \multicolumn{2}{|c|}{ Variables } & Factor loading & AVE & C. $\mathrm{R}$. & Cronbach's a \\
\hline \multirow{16}{*}{ Dejima } & \multirow{4}{*}{ Settlement areas } & 0.778 & \multirow{4}{*}{0.700} & \multirow{4}{*}{0.903} & \multirow{4}{*}{0.856} \\
\hline & & 0.853 & & & \\
\hline & & 0.863 & & & \\
\hline & & 0.848 & & & \\
\hline & \multirow{3}{*}{$\begin{array}{l}\text { Dissemination of } \\
\text { western studies }\end{array}$} & 0.867 & \multirow{3}{*}{0.696} & \multirow{3}{*}{0.872} & \multirow{3}{*}{0.781} \\
\hline & & 0.867 & & & \\
\hline & & 0.764 & & & \\
\hline & \multirow{3}{*}{$\begin{array}{l}\text { School } \\
\text { establishment }\end{array}$} & 0.805 & \multirow{3}{*}{0.688} & \multirow{3}{*}{0.868} & \multirow{3}{*}{0.774} \\
\hline & & 0.848 & & & \\
\hline & & 0.834 & & & \\
\hline & \multirow{3}{*}{$\begin{array}{l}\text { Expansion of } \\
\text { surrounding } \\
\text { facilities }\end{array}$} & 0.858 & \multirow{3}{*}{0.663} & \multirow{3}{*}{0.854} & \multirow{3}{*}{0.746} \\
\hline & & 0.865 & & & \\
\hline & & 0.710 & & & \\
\hline & \multirow{3}{*}{$\begin{array}{l}\text { Foundation of } \\
\text { modernization }\end{array}$} & 0.873 & \multirow{3}{*}{0.749} & \multirow{3}{*}{0.899} & \multirow{3}{*}{0.832} \\
\hline & & 0.885 & & & \\
\hline & & 0.836 & & & \\
\hline \multirow{16}{*}{$\begin{array}{l}\text { Choryang } \\
\text { Waegwan }\end{array}$} & \multirow{4}{*}{ Settlement areas } & 0.787 & \multirow{4}{*}{0.695} & \multirow{4}{*}{0.885} & \multirow{4}{*}{0.809} \\
\hline & & 0.825 & & & \\
\hline & & 0.887 & & & \\
\hline & & 0.833 & & & \\
\hline & \multirow{3}{*}{$\begin{array}{l}\text { Dissemination of } \\
\text { western studies }\end{array}$} & 0.834 & \multirow{3}{*}{0.624} & \multirow{3}{*}{0.831} & \\
\hline & & 0.847 & & & 0.797 \\
\hline & & 0.776 & & & \\
\hline & & 0.788 & & & \\
\hline & $\begin{array}{l}\text { School } \\
\text { establishment }\end{array}$ & 0.896 & 0.602 & 0.815 & 0.881 \\
\hline & & 0.810 & & & \\
\hline & Expansion of & 0.760 & & & \\
\hline & surrounding & 0.798 & 0.680 & 0.864 & 0.867 \\
\hline & facilities & 0.908 & & & \\
\hline & & 0.816 & & & \\
\hline & $\begin{array}{l}\text { Foundation of } \\
\text { modernization }\end{array}$ & 0.846 & 0.720 & 0.885 & 0.809 \\
\hline & & 0.882 & & & \\
\hline
\end{tabular}


[Table 2] Correlation and Discriminant Validity

\begin{tabular}{|c|c|c|c|c|c|c|c|}
\hline \multicolumn{2}{|c|}{ Variables } & AVE & 1 & 2 & 3 & 4 & 5 \\
\hline \hline \multirow{4}{*}{ Dejima } & Settlement areas & 0.700 & 0.836 & & & & \\
\cline { 2 - 8 } & Dissemination of western Studies & 0.696 & 0.770 & 0.834 & & & \\
\cline { 2 - 8 } & School Establishment & 0.688 & 0.763 & 0.768 & 0829 & & \\
\cline { 2 - 8 } & Expansion of Surrounding Facilities & 0.663 & 0.698 & 0.748 & 0.684 & 0.811 & \\
\cline { 2 - 8 } & Foundation of modernization & 0.749 & 0.626 & 0.691 & 0.623 & 0.572 & 0.865 \\
\hline \hline \multirow{4}{*}{$\begin{array}{l}\text { Choryang } \\
\text { Waegwan }\end{array}$} & Settlement areas & 0.695 & 0.833 & & & & \\
\cline { 2 - 8 } & Dissemination of western Studies & 0.624 & 0.483 & 0.789 & & & \\
\cline { 2 - 8 } & School Establishment & 0.602 & 0.432 & 0.218 & 0.775 & & \\
\cline { 2 - 8 } & Expansion of Surrounding Facilities & 0.680 & 0.525 & 0.504 & 0.418 & 0.824 & \\
\cline { 2 - 8 } & Foundation of modernization & 0.720 & 0.446 & 0.224 & 0.346 & 0.279 & 0.848 \\
\hline
\end{tabular}

\subsubsection{Verification of Structural Model}

The structural model uses Smart PLS 2.0 and the structural coefficient is used to derive the path coefficient and the coefficient of determination $\left(\mathrm{R}^{2}\right)$ between the variables of the research model. The coefficients of determination $\left(R^{2}\right)$ for Dissemination of western studies (0.593), School establishment (0.483), Expansion of surrounding facilities (0.387) and Foundation of modernization (0.500) were high in Dejima. The coefficients of determination $\left(R^{2}\right)$ for Dissemination of western studies (0.234) and Expansion of surrounding facilities (0.275) were high. School establishment (0.187) and Foundation of modernization (0.150) were middle in Choryang Waegwan.

[Table 3] Hypotheses Results

\begin{tabular}{|c|c|c|c|}
\hline \multirow{2}{*}{} & Hypotheses Contents & \multicolumn{2}{c|}{ Results } \\
\cline { 3 - 4 } & Settlement areas $->$ Dissemination of western studies & Dejima & $\begin{array}{c}\text { Choryang } \\
\text { Waegwan }\end{array}$ \\
\hline \hline H1-1 & Settlement areas $>$ School establishment & Accept \\
\hline H1-2 & Settlement areas $->$ Expansion of surrounding facilities & Accept & Accept \\
\hline H1-3 & Accept & Accept \\
\hline H2-1 & Dissemination of western studies $>>$ Foundation of modernization & Accept & \multirow{2}{*}{ Reject } \\
\hline H2-2 & Schtablishment $>$ Foundation of modernization & Accept & Accept \\
\hline H2-3 & Expansion of surrounding facilities $>$ Foundation of modernization & Reject & Reject \\
\hline
\end{tabular}


An Empirical Study on the Development of Intercultural Network in Northeast Asian Sea Region - Focusing on the Foreigner Residence of Deiima and Choryang Waegwan -

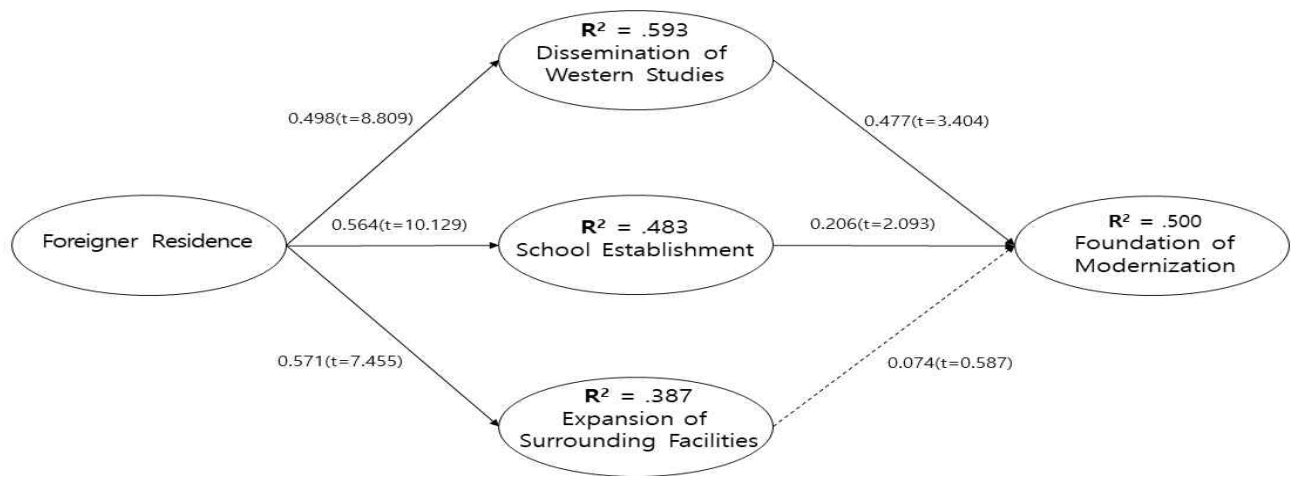

[Fig. 2] The Results of Research Model of Dejima

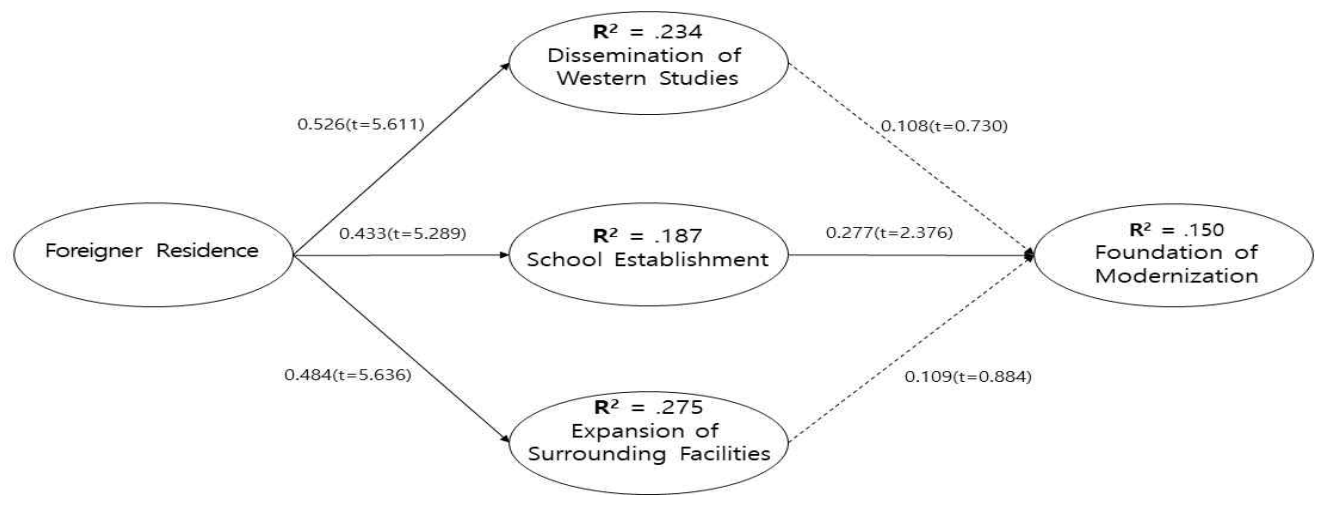

[Fig. 3] The Results of Research Model of Choryang Waegwan

The empirical analysis of Dejima in the research model is as follows. In hypothesis H1-1, settlement areas and the spread of western studies $(\beta=0.498, t=8.809, p<0.05)$ were found to have a significant effect. This means that settlement areas residence influences the spread of western studies. In hypothesis H1-2, settlement areas and school establishment ( $\beta=0.564$, $\mathrm{t}=10.129$, $\mathrm{p}<0.05)$ were found to have a significant effect. This means that settlement areas affects the school establishment. In the hypothesis H1-3, settlement areas and expansion of surrounding facilities $(\beta=0.571, \mathrm{t}=7.455, \mathrm{p}<0.05)$ were found to have a significant effect. This means that settlement areas affects the expansion of the surrounding facilities. In hypothesis H2-1, the dissemination of western studies and the foundation of modernization $(\beta=0.477$, $\mathrm{t}=3.404, \mathrm{p}<0.05)$ had a significant effect. This means that the dissemination of western studies influences the foundation of modernization. In hypothesis H2-2, school establishment and the foundation of modernization $(\beta=0.206, t=2.093, p<0.05)$ had a significant effect. This is because 
school establishment influences the foundation of modernization. In hypothesis H2-3, the expansion of the surrounding facilities and foundation of modernization $(\beta=0.074, t=0.587$, $\mathrm{p}<0.05)$ did not show a significant effect. This means that school establishment does not affect the foundation of modernization.

The empirical analysis of Choryang Waegwan in the research model is as follows. In hypothesis H1-1, settlement areas and the spread of western studies $(\beta=0.526, t=5.611, p<0.05)$ were found to have a significant effect. This means that settlement areas influences the spread of western studies. In hypothesis H1-2, settlement areas and school establishment $(\beta=0.433$, $\mathrm{t}=5.289, \mathrm{p}<0.05)$ were found to have a significant effect. This means that settlement areas affects the school establishment. In the hypothesis H1-3, settlement areas and expansion of surrounding facilities $(\beta=0.484, t=5.636, p<0.05)$ were found to have a significant effect. This means that settlement areas affects the expansion of the surrounding facilities. In hypothesis H2- 1 , the dissemination of western studies and foundation of modernization $(\beta=0.108, t=0.730$, $\mathrm{p}<0.05$ ) did not show a significant effect. This means that the dissemination of western studies does not influence the foundation of modernization. In hypothesis H2-2, school establishment and the foundation of modernization $(\beta=0.277, t=2.376, p<0.05)$ had a significant effect. This is because school establishment influences the foundation of modernization. In hypothesis H2-3, the expansion of the surrounding facilities and foundation of modernization $(\beta=0.109, t=0.884$, $\mathrm{p}<0.05)$ did not show a significant effect. This means that school establishment does not affect the foundation of modernization.

\section{Conclusion}

The most famous foreign settlement areas in Japan and Korea are Dejima and Choryang Waegwan respectively. The Japanese government stopped Christian missionary work and accepted a Portuguese who lived in various regions. Dejima was built in 1636 to strictly monitor trade. At Choryang Waegwan, only men who were entrusted with the diplomatic and trade work of the Japanese government could live. The Korean government also established border zones of Waegwan, such as door, and restricted cross-cultural exchanges between Koreans and Japanese by prohibiting the entrance of the public.

This study is an empirical study that investigates the operation and living in settlement areas in the Northeast Asian Sea Region cross-cultural network. The summary of the study is as follows. First, settlement areas and the spread of western studies were found to have a significant effect in Dejima and Choryang Waegwan. Second, settlement areas and school 
An Empirical Study on the Development of Intercultural Network in Northeast Asian Sea Region - Focusing on the Foreigner Residence of Deiima and Choryang Waegwan -

establishment were found to have a significant effect in Dejima and Choryang Waegwan. Third, settlement areas and expansion of surrounding facilities were found to have a significant effect. Fourth, the dissemination of western studies and foundation of modernization had a significant effect in Dejima. However, it does not have a significant effect in Choryang Waegwan. Fifth, school establishment and the foundation of modernization had a significant effect in Dejima and Choryang Waegwan. Sixth, the expansion of the surrounding facilities and foundation of modernization did not show a significant effect in Dejima and Choryang Waegwan.

Based on this study, the foreign residence of Dejima and Choryon suggests an empirical model for the formation and foundation of modernization. The empirical analysis confirms the results of the study that the foreign residence affects the foundation of modernization in Dejima and Choryang Waegwan. So far, there are few existing studies on the residence of foreigners and the foundation of modernization. This study is meaningful contribution to empirical existing studies on the foreigner's settlement areas and the foundation of modernization "on the Intercultural Network in Northeast Asian Sea Region".

\section{Acknowledgement}

This work was supported by the Ministry of Education of the Republic of Korea and the National Research Foundation of Korea in 2017 (NRF-2017S1A6A3A01079869).

\section{References}

[1] M. Kong, A Study on Choryang Waegwan through Dejima as a Modernisation of Japan, Journal of North-east Asian Cultures, (2018), No.55, pp.139-156, DOI: 10.17949/jneac.1.55.201806.008

[2] Y. J. Chung, A Study on the Construction of Choryang-gaeksa, The Korea-Japan Historical Review, (2010), No.37, pp.117-170, UCI: G704-001395.2010..37.003

[3] H. Yang, Local People's Everyday Lives and Deviation in Terms of 'Crimes' around Waegwan in the Late Joseon Dynasty, Journal of Koreanology, (2011), No.40, pp.233-264, UCI: G704-001560.2011..40.012

[4] M. H. Ye, C. G. Choi, M. H. Heo, Study in Relation to Wakan During the Chosen Dynasty: (with Special reference to Early Chosen Dynasty), Journal of natural sciences, (1991), Vol.8, pp.53-60.

[5] O. K. Je, Modern tourism character of Korean observation tourist to Japan in Japanese imperialism era -Focused on the concept of two-facedness of modernity(Logos-Eros)-, The Japanese Modern Association of Korea, (2017), No.56, pp.285-300, DOI: 10.16979/jmak..56.201705.285

[6] K. Kim, Prostitution case(交奸事件) in late modern times Waegwan(倭館) and Prostitutes(遊女) of Dejima 
(出島), Jeonbuk Historical Society, JEONBUK SAHAK, (2015), No.46, pp.287-314, UCI: G704-002047.2015..46.013

[7] J. Jeon, An Investigation of the Characteristics and Progress of Education in Busan during the Period of Korean Empire -The Field of Education as a Place of Cultural Exchange-, The Japanese Modern Association of Korea, (2013), No.39, pp.193-213, DOI: 10.16979/jmak..39.201302.193

[8] G. Chung, Japanese Korean Language Education and the Formation of Translation Police during 1872-1910s, The Studies in Korean Literature, (2007), No.32, pp.7-55, DOI: 10.20881/sk1.2007..32.001

[9] H. Yang, The People of Choryang after the Opening of Portsand the Formation of a Modern Space, Korean National Culture, (2012), No.44, pp.211-249, UCI: G704-001560.2012..44.002

[10] http://kostma.korea.ac.kr/knowledge/, Nov 23 (2019)

[11] https://ravel.at-nagasaki.jp/en/s/feature/settlement/top/, Nov 23 (2019)

[12] C. Cha, The Reclamation of Busan North Harbor and the making of the Urban District, Journal of Koreanology, (2006), No.28, pp.1-36. 